\title{
Value of copper-associated protein in diagnostic assessment of liver biopsy
}

\author{
PAOLO GUARASCIO, FRANCES YENTIS, UGUR CEVIKBAS, BERNARD PORTMANN, \\ ROGER WILLIAMS
}

From the Liver Unit, King's College Hospital, Denmark Hill, London SE5

SUMMARY Of 1361 consecutive liver biopsy specimens, $24 \%$ contained orcein-positive granules. The highest incidence of positivity was found in biliary disease $(90.9 \%)$, long before cirrhosis had developed, whereas in chronic non-primarily biliary disease, positive results were almost exclusively in patients with well established cirrhosis. Orcein-positive granules were never found in acute liver disease. These granules were also demonstrated in tumour cells of primary hepatocellular tumours (benign 4 of 4 cases; malignant 9 of 37 cases), while all the secondary tumour deposits were negative. In our view the additional information obtained by this technique warrants its adoption as a routine procedure.

Orcein has become widely used for the demonstration of copper-associated protein which accumulates within hepatocyte lysosomes in various pathological conditions ${ }^{12}$ as well as for staining elastic fibres and hepatitis B surface antigen..$^{3-7}$ Although the exact nature of this sulphydryl-rich copperprotein complex has not been elucidated, its demonstration on a liver biopsy specimen provides valuable information about the duration or stage of chronic cholestatic liver disease. ${ }^{89}$

We describe here the pattern and incidence of orcein-positive granules found in 1361 liver biopsies obtained for diagnostic purposes from adult patients with a wide range of liver diseases. One aim was to estimate the value of this histological feature in reaching a diagnosis and on the basis of this to decide whether orcein is worth including in the routine tissue sections stained.

\section{Material and methods}

The 1361 liver biopsy specimens, obtained with a Trucut needle (Travenol Laboratories), were fixed in $10 \%$ formol saline, embedded in paraffin, cut at $4 \mu \mathrm{m}$ and stained by standard histological methods (haematoxylin and eosin, Gordon and Sweets' silver method; Perls's Prussian blue; chromotrope aniline blue; and, in a few cases, periodic acid-Schiff procedure after diastase treatment). Orcein staining

Accepted for publication 14 July 1982 was performed according to the method of Shikata et $\mathrm{al}^{4}$ with two modifications: (i) sections were oxidised in a solution of $0.5 \%$ potassium permanganate $(47.5$ $\mathrm{ml})$ and $3 \%$ concentrated sulphuric acid $(2.5 \mathrm{ml})$ which is similar to the solution used in the first step of the silver method for reticulin; (ii) optimal staining in the orcein solution was obtained in $90 \mathrm{~min}$ instead of $4 \mathrm{~h}$. Two hundred consecutive specimens were also stained with rhodanine which gives a red-orange precipitate with copper. In order to assess the effect of duration of fixation on orcein and rhodanine staining, multiple needle samples were obtained post mortem from the liver of three patients with advanced primary biliary cirrhosis, in whom orceinpositive granules had been previously identified. These specimens were immersed in $10 \%$ formol saline for various periods of time, being processed one a day for the first week and then one a week for three months, and subsequently stained with orcein $\mathcal{N}$ and rhodanine.

Without knowledge of the anatomoclinical diagnosis, all 1361 stained sections were graded for the presence of positive granules on a 0 to 4 scale as follows: $0=$ no positive granules; $1=$ few isolated $\stackrel{\varrho}{\subset}$ cells containing small, sparse granules, not seen at $\Phi_{\overparen{D}}$ low magnification; 2 = moderate number of granules seen at low magnification; 3 = numerous cells loaded with heavily stained, coarse granules, mainly $\underset{\mathbb{D}}{\mathbb{D}}$ confined to periportal and paraseptal areas; $4=\frac{?}{\mathbb{Q}}$ reserved for widespread deposition of granules $\stackrel{\odot}{\circ}$ throughout the lobule. 
The final diagnosis in each case was based on histological and clinical evaluation, including biochemical and immunological tests, and, if necessary, information from liver ultrasound, ${ }^{99} \mathrm{Tc}$ sulphur colloid liver scan, and ERCP examination. The criteria of Rubin et al ${ }^{10}$ and Scheuer " were used to divide primary biliary cirrhosis into four stages of disease.

\section{Results}

The orcein-positive material was seen as fine to coarse dark brown/black intracytoplasmic granules on a light brown background. They were easily distinguished from other pigments or inclusions found within liver cells such as bile, lipofuscin, haemosiderin, Dubin-Johnson pigment, alpha-1antitrypsin globules, $\mathrm{HBsAg}$ orcein-positive material, and were not stained by the periodic acidSchiff method after diastase. Darkening of the background, usually due to ageing of either the permanganate of the orcein solution or to defective processing, was not a problem, since staining of the granules then became deeper. Optimal assessment with highly stained sections was achieved by renewing the oxidising and staining solution every three weeks. In all instances, the granules stained by orcein were more numerous and larger than those stained by rhodanine, although their distribution in the tissue was similar. Orcein staining was not affected by the duration of fixation even after the tissue had been stored for three months in formalin, whereas rhodanine staining gradually faded, becoming negative after four weeks of the same treatment.

Three main patterns of distribution of orcein- positive granules were seen which were found either alone or together on the same biopsy.

(a) Periportal or paraseptal. The hepatocytes containing orcein-positive granules are regularly located around the portal tracts and along the fibrous septa (Fig. 1).

(b) Randomly, within individual or groups of hepatocytes, often enmeshed within fibrous tissue (Fig. 2).

(c) Widespread deposition in most of the hepatocytes throughout the lobules (Fig. 3).

Orcein-positive granules were found in 337 out of the $1361(24.7 \%)$ consecutive liver biopsies (Table 1). The conditions not associated with orcein-positive granules deposition are listed in Table 2.

\section{FREQUENCY AND PATTERN OF COPPER- \\ ASSOCIATED PROTEIN DEPOSITION IN DISEASE CATEGORIES}

\section{Biliary diseases}

Orcein-positive granules were found in 162 of 167 $(97 \%)$ biopsies from patients with primary biliary cirrhosis (PBC). They were absent only in stage I and the degree of positivity tended to increase with the progression of the disease (Table 3 ). In the first two stages small and scanty granules were contained in a few normal looking hepatocytes at the periphery of some portal tracts. In contrast, stages III and IV were characterised by prominent periportal and paraseptal granular deposits evenly highlighting the parenchymal limiting plates. In these late stages the presence of orcein-positive deposits could have been anticipated on haematoxylin and eosin stained sections, by the presence of characteristic changes:

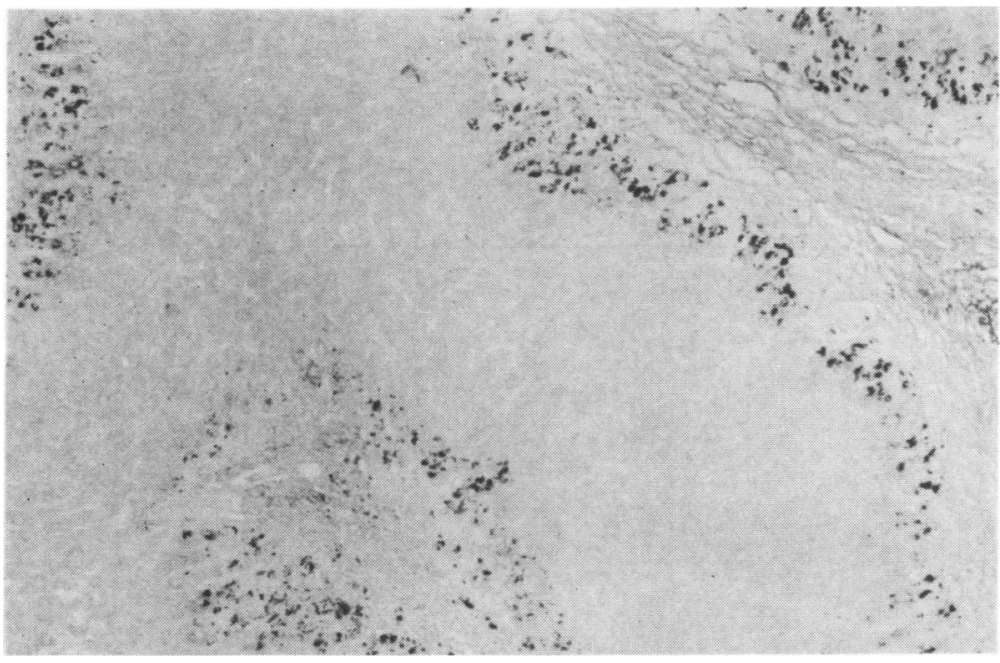

Fig. 1 Primary biliary cirrhosis. Uniform distribution of orcein granules (grade 3) highlighting the parenchymal limiting plates. Orcein $\times 80$ 


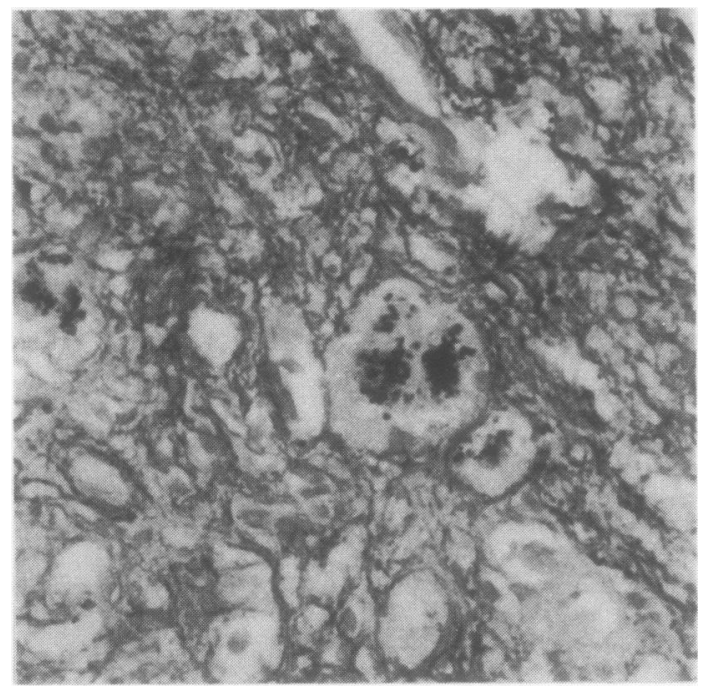

Fig. 2 Alcoholic cirrhosis. A few hepatocytes loaded with copper-associated protein are deeply enmeshed within fibrous tissue. Orcein $\times 320$

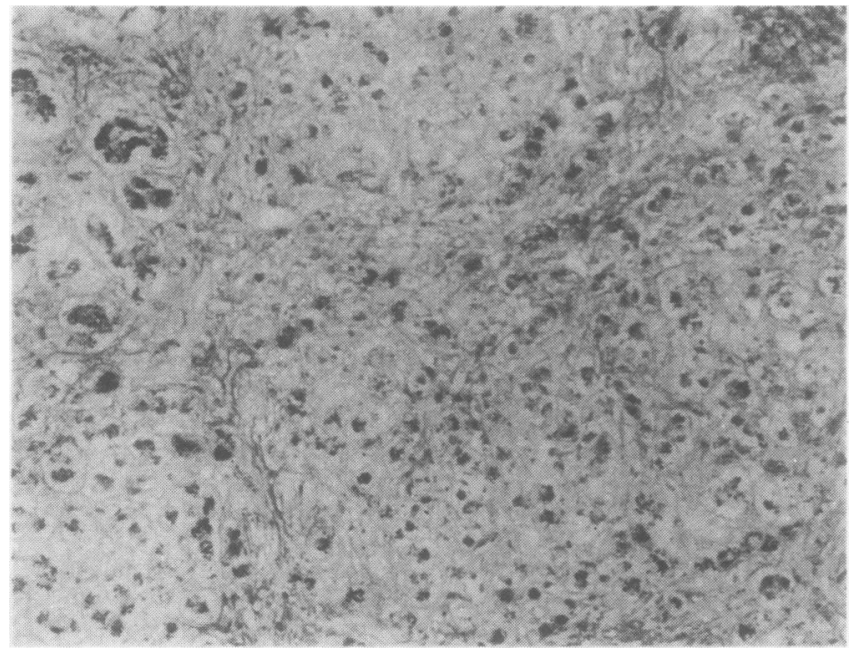

the cells of the limiting plates separated by extremely loose connective tissue were ballooned and variably loaded with bile pigment and a few hyaline inclusions (Fig. 4), whereas in other places shrinkage of the cells transformed the plates into pseudoductules (Fig. 5).

Fifteen of $16(93.7 \%)$ biopsies from patients with sclerosing cholangitis showed a pattern of orceinpositive deposits identical to that seen in the late stages of PBC, as were the changes in the limiting plates seen on haematoxylin and eosin preparations. Out of 16 biopsies from patients with proven extrahepatic biliary obstruction, five showed mild to moderate periportal orcein-positive granule deposition. The mean duration of symptoms prior to biopsy was longer than one year in those five patients compared with $6 \cdot 1$ months (range 1-12 months) in seven of the 11 patients with orcein-negative biopsy in whom a reliable estimate of the clinical history could be obtained. Six of eight biopsies with features of chronic cholangitis, but no established aetiology, showed orcein-positive granules with a similar

Table 1 Conditions associated with copper-associated protein

\begin{tabular}{|c|c|c|c|c|c|c|c|}
\hline \multirow[t]{2}{*}{ Condition } & \multirow{2}{*}{$\begin{array}{l}\text { No of } \\
\text { biopsies }\end{array}$} & \multirow{2}{*}{$\begin{array}{l}\text { No of positive } \\
\text { biopsies (\%) }\end{array}$} & \multicolumn{4}{|c|}{ Grading of deposition } & \multirow{2}{*}{ 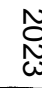 } \\
\hline & & & 4 & 3 & 2 & $l$ & \\
\hline Primary biliary cirrhosis & 167 & $162(97)$ & 16 & 68 & 55 & 23 & O \\
\hline Sclerosing cholangitis & 16 & $15(93 \cdot 7)$ & - & 3 & 8 & 4 & 0 \\
\hline Intrahepatic ductular hypoplasia & 1 & $1(100)$ & 1 & - & - & - & $=$ \\
\hline Large duct obstruction & 16 & $5(31)$ & - & - & 2 & 3 & $\mathscr{D}$ \\
\hline "Chronic cholangitis" & 8 & $6(75)$ & - & - & 3 & 3 & $\stackrel{+}{+}$ \\
\hline Alcoholic cirrhosis & 107 & $44(41)$ & - & 1 & 16 & 27 & 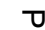 \\
\hline Cryptogenic cirrhosis & 86 & $40(46)$ & - & 6 & 15 & 19 & $\overline{0}$ \\
\hline CAH cirrhotic & 153 & $47(30 \cdot 7)$ & - & 6 & 17 & 24 & 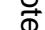 \\
\hline CAH precirrhotic & 126 & $2(1.5)$ & - & - & - & 2 & 0 \\
\hline$\alpha_{1} \mathrm{AT}$ deficiency associated cirrhosis & 4 & $2(50)$ & - & - & - & 2 & $\overrightarrow{\mathrm{D}}$ \\
\hline Focal nodular hyperplasia* & 2 & $2(100)$ & - & - & 2 & - & อ \\
\hline Hepatocellular adenoma ${ }^{*}$ & 2 & $2(100)$ & - & - & 2 & - & O \\
\hline Hepatocellular carcinoma* & 37 & $9(24 \cdot 3)$ & - & 1 & 3 & 5 & \\
\hline
\end{tabular}

Fig. 3 Widespread deposition of positive granules in a case of intrahepatic bile duct hypoplasia. Orcein $\times 260$ 
Table 2 Conditions not associated with copper-associated protein

\begin{tabular}{lc}
\hline & $\begin{array}{c}\text { Noof } \\
\text { biopsies }\end{array}$ \\
\hline Acute cholangitis & 8 \\
Acute cholestasis & 7 \\
Alcoholic liver disease (non-cirrhotic) & 77 \\
Fatty infiltration & 68 \\
Acute hepatitis and variants & 91 \\
Confluent necrosis & 72 \\
Chronic persistent hepatitis & 85 \\
Granulomatous hepatitis & 17 \\
Haemochromatosis & 2 \\
Venous outflow block & 21 \\
Non-specific changes & 153 \\
Miscellaneous & 6 \\
Metastatic tumours & 31 \\
\hline
\end{tabular}

Table 3 Copper-associated protein deposition in relation to stage of primary biliary cirrhosis

\begin{tabular}{|c|c|c|c|c|c|c|}
\hline \multirow{2}{*}{$\begin{array}{l}\text { Stage of } \\
\text { disease }\end{array}$} & \multicolumn{5}{|c|}{ Grade of orcein deposit } & \multirow{2}{*}{$\begin{array}{l}\text { Total no } \\
\text { (\% positive) }\end{array}$} \\
\hline & 0 & 1 & 2 & 3 & 4 & \\
\hline I & \multicolumn{2}{|c|}{$(62 \cdot 5 \%)(37 \cdot 5 \%)$} & 0 & () & 0 & \multirow{2}{*}{$\begin{array}{c}8 \\
(37 \cdot 5 \%) \\
4 \\
(100 \%)\end{array}$} \\
\hline II & 0 & $\begin{array}{c}2 \\
(50 \%)\end{array}$ & $\stackrel{2}{(50 \%)}$ & () & 0 & \\
\hline III & () & $\begin{array}{c}9 \\
(23.7 \%)\end{array}$ & $(44.7 \%$ & 12 & 0 & $\begin{array}{c}38 \\
(100 \%)\end{array}$ \\
\hline IV & () & $\begin{array}{l}9 \\
(7.7 \%)\end{array}$ & 36 & $\begin{array}{c}56 \\
(47.9 \%)\end{array}$ & $\begin{array}{l}16 \\
(13.7 \%\end{array}$ & $\begin{array}{l}117 \\
(100 \%)\end{array}$ \\
\hline
\end{tabular}

periportal distribution. A biopsy from a 20-year-old woman with intrahepatic ductular hypoplasia showed the most intense orcein staining with widespread deposition of coarse granules throughout the parenchyma (Fig. 3), whereas haematoxylin and eosin revealed extensive ballooning of almost all liver cells with heavy bile pigmentation.

No orcein deposits were seen in acute cholangitis (eight cases) nor in severe acute cholestasis (drug induced, two cases; following viral hepatitis, four cases; and benign recurrent, one case).

\section{Cirrhosis}

In patients with alcoholic liver disease orcein-positive granules were found only in those with established cirrhosis. The distribution in the tissue was patchy and usually confined to groups of hepatocytes enmeshed within fibrous septa (Fig. 2). Less commonly there was a more uniform periportal pattern of deposition and in those cases the liver cell damage and limiting plate disruption resembled that in late primary biliary cirrhosis.

Similarly, in chronic non-alcoholic liver disease orcein-positive granules were found almost exclusively in biopsies showing a definite cirrhotic transformation whether cryptogenic (37 cases), following chronic active hepatitis (47 cases), or associated with alpha-1-antitrypsin deficiency (4 cases). The distribution within the nodule was similar to that found in alcoholic cirrhosis and the presence of orcein-positive granules did not correlate with the degree of limiting plate disruption (piecemeal necrosis).

Serum alkaline phosphatase activity was significantly higher in 41 cirrhotics of primarily nonbiliary type with copper-associated protein-positive granules on biopsy, than in 38 control cirrhotics (mean values of 204.5 and $114.4 \quad \mathrm{IU} / 100 \mathrm{ml}$ respectively, normal values $25-85 \mathrm{IU} / 100 \mathrm{ml}, \mathrm{p}<$ $0 \cdot 001)$. There was no significant difference between the two groups with respect to serum bilirubin and $\gamma \mathrm{GT}$ values.

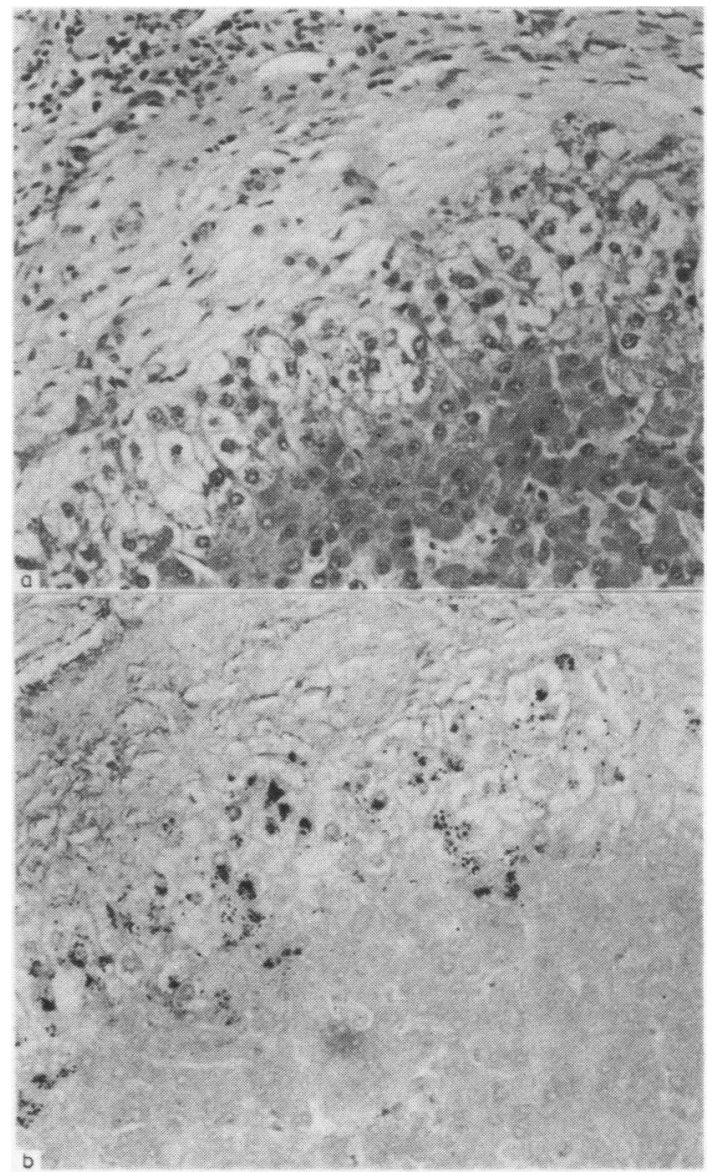

Fig. 4 Ballooning type of limiting plate damage with copper-associated protein deposition in a case of primary biliary cirrhosis (a) Haematoxylin and eosin $\times 280$

(b) Orcein $\times 280$ 


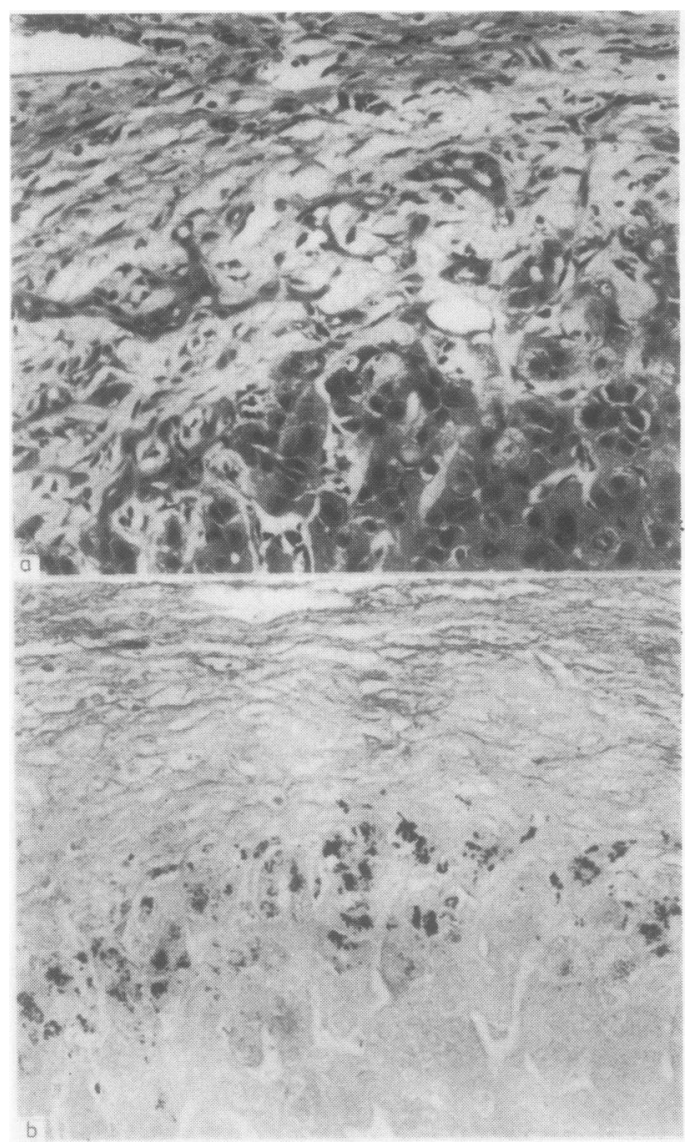

Fig. 5 Other type of limiting plate disruption in primary biliary cirrhosis with cell atrophy and pseudoductular transformation (a) Haematoxylin and eosin $\times 280$ (b) Orcein $\times 280$

\section{Benign and malignant tumours}

Two samples of hepatocellular adenoma from male patients who had been taking androgens for 10 and 16 yr continuously, showed random accumulation of copper-associated protein within the tumour cells. In the two cases of focal nodular hyperplasia, one of which was a young girl taking oral contraceptives, there were orcein deposits within hyperplastic hepatocytes located at the margin or among some of the fibrous septa. Discrete deposits were found within tumour cells of nine out of 37 cases of hepatocellular carcinoma, two of which also contained bile pigment. All secondary tumours were orcein-negative.

\section{Discussion}

The granular material stained with the orcein method is a sulphydryl-rich copper-associated protein ' located within the liver cell lysosomes. ${ }^{12}$ Our data have shown that the staining is not affected by the duration of formalin fixation whereas rhodanine staining, which is the result of a coloured precipitate with copper, is gradually reduced, presumably by copper extraction in the formalin solution. Furthermore, the orcein staining is simple to perform, reproducible and easy to interpret, the positive granules being clearly distinguishable from any other pigments and inclusions seen on histological examination.

The exact mechanism of copper-associated protein deposition has not yet been fully elucidated. There is some correlation between the increased concentration of hepatic copper and the grade of orcein-staining granules in biopsy specimens. ${ }^{91314}$ Jain ${ }^{14}$ proposed that the copper-associated protein might be a cellular component inducible by high copper concentration, which provides protection to the cell by incorporating the bound copper into lysosomes.

The striking association of copper-associated protein deposits with chronic biliary diseases suggests that an interference with bile flow is of major importance. In theory, a pathological process acting at any level of the biliary system, from the bile canaliculus to the large extrahepatic bile duct, should have the same effect. This may well be reflected in the pattern of orcein deposition. Regular periportal and paraseptal deposition is the pattern of long-standing either intra or extrahepatic biliary disease. The degree of granular deposition appears to increase with the stage or the duration of the disease and in the present series the most severe lesion was found in the patient with a 20-year history of an obstructive type of jaundice due to intrahepatic bile duct hypoplasia. In cirrhosis not of primarily biliary origin, there was a patchy deposition within groups of cells surrounded by fibrous tissue, suggesting a disconnection of those cells from the ductular system. In the few cases in which the pattern of copper-associated protein did resemble that seen in primary biliary cirrhosis, serum alkaline phosphatase was significantly raised and there was the same type of limiting plate disruption as that seen in primary biliary cirrhosis. This suggests that the extensive remodelling of the liver architecture which occurs in advanced cirrhosis of any aetiology may produce intrahepatic bile duct distortion with subclinical cholestasis.

The percentage of patients with orcein-positive granules $-24.7 \%$ in this consecutive series of biopsies taken for diagnostic purposes - is higher than that found by Vyberg. ${ }^{15}$ This is mainly related to the high proportion of biliary diseases in our series, which reflects the greater diagnostic problem of obstructive type jaundice and the need for referral to a specialised unit. 
From a diagnostic point of view it is of interest that none of the acute liver diseases, whatever the aetiology or the degree of histological cholestasis, were associated with copper-associated protein deposition on biopsy. For example, one of the patients eventually proven to have a high duct carcinoma, was initially thought on the basis of her history, clinical presentation and histology, to have a Brufen-induced cholestatic hepatitis the only contradictory finding being the presence of abundant copper-associated protein deposition.

A negative orcein staining was also meaningful in patients with chronic liver disease with already significant fibrosis or cirrhosis on histological examination, since it ruled out a diagnosis of PBC or sclerosing cholangitis. In agreement with other authors $^{18915}$ we found copper-associated protein helpful in distinguishing PBC from chronic active hepatitis at the precirrhotic stage of these diseases. Although copper-associated protein was very occasionally seen in precirrhotic chronic active hepatitis, it was invariably present in PBC by the second stage. Jain $e^{2} a^{14}$ found 7 of 16 patients with chronic active hepatitis had positive orcein granules, but did not mention whether cirrhosis had developed. In cirrhosis not primarily of biliary origin, the finding of copper-associated protein provides further histological confirmation of cirrhotic transformation, which can be of considerable help with the sampling error inherent in small needle biopsy specimens.

The demonstration of copper associated protein deposits in focal nodular hyperplasia, hepatocellular adenoma and hepatocellular carcinoma is in accord with and extends our earlier observations. ${ }^{16}$ Its occurrence within tumour cells of about a quarter of the cases of hepatocellular carcinoma, but in none of the various types of secondary tumours found in this series, provides a further histological marker, which may be useful for distinguishing between primary and secondary liver tumours.

In our view, the presence or, in some instances, the absence of copper-associated protein in a diagnostic liver biopsy specimen provides the pathologist with valuable additional information and undoubtedly justifies the addition of orcein to the routine staining procedures of liver biopsy sections.
PG is supported by a grant from Ospedale L Spallanzani (Rome). We thank $\mathrm{K}$ Davis and $\mathbf{R}$ Senkus for preparation of the microphotographs.

\section{References}

' Salaspuro M, Sipponen P. Demonstration of an intracellular copper-binding protein by orcein staining in long-standing cholestatic liver diseases. Gut 1976;13:787-90.

${ }^{2}$ Sipponen $\mathrm{P}$. Orcein positive hepatocellular material in long standing biliary diseases. Histochemical characteristics. Scand J Gastroenterol 1976;11:545-52.

${ }^{3}$ Scheuer PJ, Maggi G. Hepatic fibrosis and collapse; histological distinction by orcein staining. Histopathology 1980;4:487-90.

${ }^{4}$ Shikata T, Uzawa T, Yoshiwara N, Akatsuka T, Yamazaki S. Staining method of Australia antigen in paraffin section. Detection of cytoplasmic inclusion bodies. Jpn J Exp Med 1974;44:25-36.

${ }^{5}$ Shikata T. Australia antigen in liver tissue. An immunofluorescent and immunoelectron microscopic study. Jpn J Exp Med 1973;43:231-45.

- Portmann B, Galbraith RM, Eddleston ALWF, Zuckerman AJ, Williams R. Detection of $\mathrm{HBsAg}$ in fixed liver tissue. Use of a modified immunofluorescent technique and comparison with histochemical methods. Gut 1976;17:1-9.

${ }^{7}$ Deodhar KP, Tapp E, Scheuer PJ. Orcein staining of hepatitis B antigen in paraffin sections of liver biopsies. J Clin Pathol 1975;28:66-70.

${ }^{8}$ Goldfischer S, Popper H, Sternlieb I. The significance of variations in the distribution of copper in liver disease. Am J Pathol 1980;99:715-30.

9 Ludwig J, McDonald GSA, Dickson ER, Elveback LR, McCall JT. Copper stains and the syndrome of primary biliary cirrhosis. Arch Pathol Lab Med 1979;103:467-70.

${ }^{10}$ Rubin E, Schaffner F, Popper H. Primary biliary cirrhosis chronic non-suppurative destructive cholangitis. Am J Pathol 1965;46:387-407.

"Scheuer PJ. Primary biliary cirrhosis. Proc Roy Soc Med 1967;60:1257-60.

${ }^{12}$ Nakamura Y, Karino T, Ohta G. Orcein positive granules in the hepatocytes in chronic intrahepatic cholestasis. Virchows Archiv A 1979;382:21-30.

${ }^{13}$ Evans J, Newman S, Sherlock S. Liver copper levels in intrahepatic cholestasis of childhood. Gastroenterology 1978;75:875-8.

14 Jain S, Scheuer PJ, Archer B, Newman SP, Sherlock S. Histological demonstration of copper and copper-associated protein in chronic liver diseases. J Clin Pathol 1978;31:784-90.

15 Vyberg M, Thomsen P. Orcein positive granules in liver cells. Acta Path Microbiol Scand 1979;87:421-5.

${ }^{16}$ Portmann B, Cevikbas U, Melia W, Williams R. Pathology of oral contraceptive and androgenic steroid associated liver tumours. In: Davis M, Tredger JM, Williams R, eds. Drug reactions and the liver. London: Pitman Medical, 1981:290-303.

Requests for reprints to: Dr R Williams, Director, Liver Unit, King's College Hospital, Denmark Hill, London SE5, England. 